\title{
The improved technique for calculating the concrete elements strength under local compression
}

\author{
Volodymyr Pohribnyi ${ }^{1}$, Oksana Dovzhenko ${ }^{1 *}$, Iryna Kuznietsova ${ }^{1}$, and Dmytro Usenko ${ }^{1}$ \\ ${ }^{1}$ Poltava National Technical Yuri Kondratyuk University, Pershotravneviy sq., 24, Poltava, 36011, \\ Ukraine
}

\begin{abstract}
The central one-sided concrete element crushing is considered when the loading platform width is less than the element width (in threedimensional stress state conditions). A variational method in the concrete plasticity theory, which is developed in the Poltava National Technical Yuri Kondratyuk University, is proposed to calculate the strength. The formula for determining the ultimate load is based on the destruction kinematics, which is observed in the experiments, and takes into account the loading platform size ratio and the element, both concrete strength characteristics, the frictional forces between the support surface and the element. The calculation dependence is rather precise during the cubes central crushing when the element height ratio and the loading platform greater than 4 . With other geometric parameters the kinematic scheme changes, which must be taken into account when deriving the formulas for calculating the strength by the variational method. The proposed method allows considering all possible calculation schemes and determining its application limits.
\end{abstract}

\section{Introduction}

In the construction there are large concentrated loads transfer cases to concrete elements. As an example, it is possible to support the inclined colonnade reinforced concrete columns on the shell and the hyperbolic cooling tower pool wall, multi-story buildings reinforced concrete columns or suspended walls supports on concrete elements of different height and configuration in the plan that are basement part or other buildings structural parts [1]. In this case, there is a concrete local compression in the structural elements and its destruction probability from punching shear or crushing depending on the geometric dimensions that fall under the relevant design schemes adopted in the standards.

One of the reserves for improving the concrete and reinforced concrete elements operational reliability is to improve its calculation methods. It is necessary to switch from empirical dependences to other alternatives dependences, which take into account the stress-strain state and the element kinematic destruction characteristic under crushing. Thus, the strength problem solution under local compression remains an urgent task and requires further theoretical and experimental studies.

\footnotetext{
* Corresponding author: o.o.dovzhenko@gmail.com
} 
The work aim is to improve the concrete elements strength calculating method under local compression.

According to experimental studies, the ratio between loading platform length and the element height [2-5] or length, the element sides ratio [6], size effect [7], the eccentricity applied load $[3,6]$, the friction on the contact between the load (support) platform and the element surface, the concrete class and type [3, 8], loading prehistory [9] are main factors influencing the concrete crushing strength.

Most of the calculation methods [10] are based on the Bauschinger's formula and its variations, which operate at most two or three significant factors, in particular, the calculated area $A_{c 1}$ and the compressive concrete strength $f_{c d}$, then at least eight of them. This often leads to significant differences between experimental and theoretical results.

\section{The analysis of proposed design dependencies}

The normative in different periods (Fig. 1) and author's dependencies are considered and analyzed (Fig. 2, Table 1) for the local central one-sided compression. The bearing capacity was determined for the column support variant on the basement wall (Fig. 3) from concrete with a class on the compressive strength C20/25.

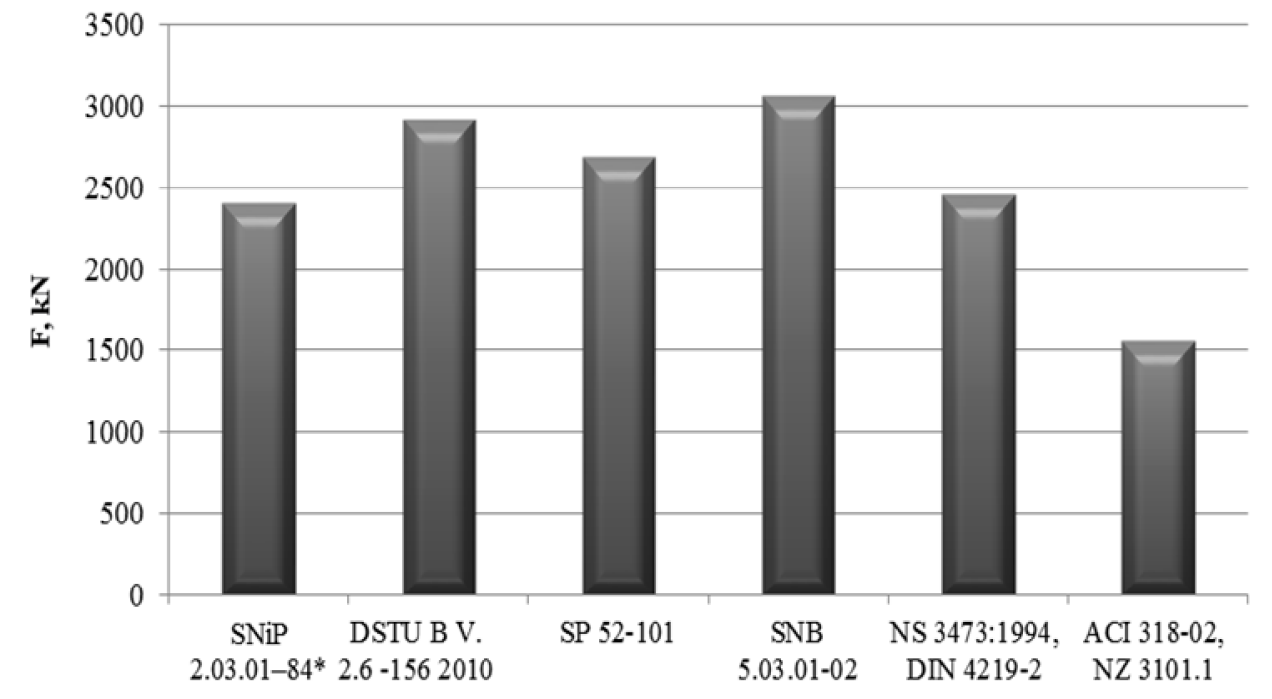

Fig. 1. Concrete elements strength under local central one-sided compression obtained according to normative documents.

As a calculations result, we can conclude that the largest bearing capacity for the considered case was obtained according to the method presented in Belarusian norms. The smallest bearing capacity was obtained according to the method presented in American and New Zealand norms (the difference between the bearing capacity values is $50 \%$ ). The theoretical strength convergence analysis with experimental for 35 samples $[11,12]$ was performed. The best statistical indicators are the normative methodology of Ukraine and Eurocode 2: for its, the theoretical strength ratio average arithmetic value to the experimental is $m=0.99$, the variation coefficient is $v=29.42 \%$.

The results most closely related to the experiments among authors has the V. Jensen's dependence with the following statistical characteristics: $m=0.84, v=28.52 \%$. At the same time, the maximal values for the considered case are obtained by the 
V. Chervonobaba's formula, the minimal values - V. Gladyshev's, and they differ more than twice.

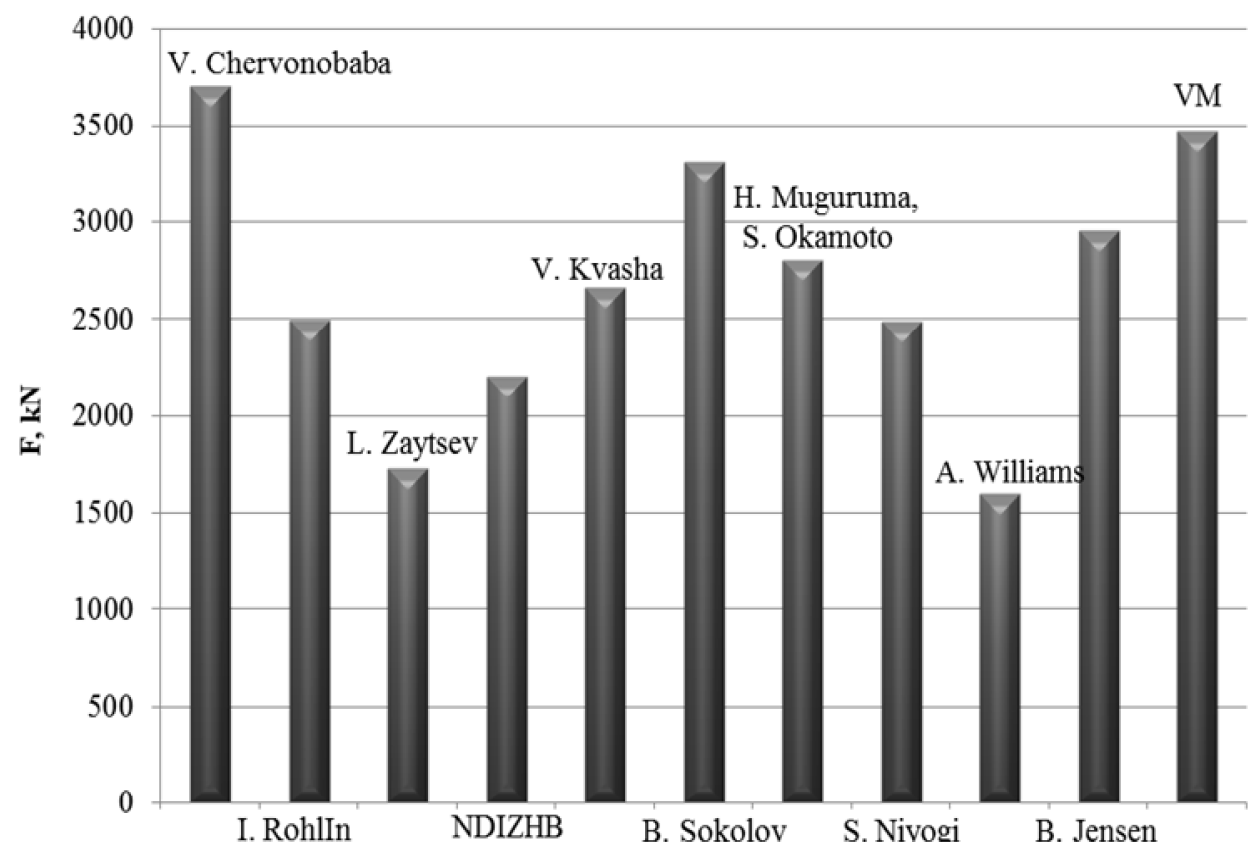

Fig. 2. Concrete elements strength under local central one-sided compression obtained according to author's methods.

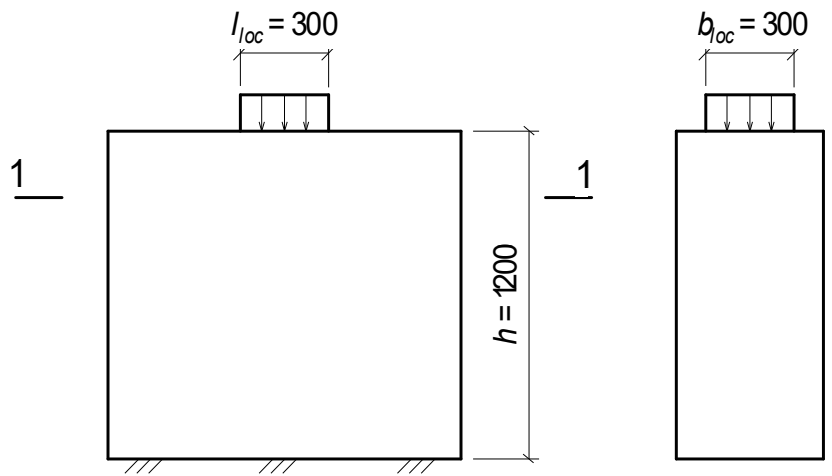

$1-1$

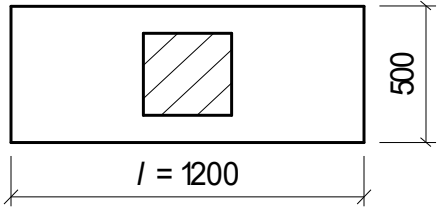

Fig. 3. Local central one-sided compression.

A large number of proposed dependencies and the results widespread scatter, necessitates the need to improve the calculation method under crushing. 
Table 1. Design dependencies proposed for concrete strength under local central one-sided compression.

\begin{tabular}{|c|c|c|}
\hline № & The author & Estimated dependencies \\
\hline 1 & Chervonobaba V.A. & $f_{c, l o c}=f_{c} \quad 4-3\left(\frac{A_{c 1}}{A_{c 0}}\right)^{\overline{2}}$ \\
\hline 2 & Rohlin I.A. & $f_{c, l o c}=f_{c}\left(\frac{A_{c 0}}{A_{c 1}}\right)^{-0,3424}$ \\
\hline 3 & Hladyshev B.M. & $f_{c, l o c}=0.4 f_{c t} \frac{h}{l_{l o c}}\left(2.3+5 \frac{l_{l o c}}{l}\right)\left(2.5-\frac{h}{l}\right)$ \\
\hline 4 & Zaytsev L.N. & $\begin{array}{c}f_{c, l o c}=\frac{f_{c} h / l_{l o c}}{\left(\frac{2}{\pi k_{3} m_{2}}\right)\left(1+\frac{f_{c}}{f_{c t}}\right)\left[1-1.41(\delta-0.1)+0.53(\delta-0.1)^{2}\right]+t}, \\
\quad k_{3}=1 ; \quad m_{2}=1.6 ; \quad \delta=\frac{l_{l o c}}{h} ; \quad t=\frac{0.75 \delta+0.275}{1.4 \delta}\end{array}$ \\
\hline 5 & NDIZHB & $\begin{array}{c}f_{c, l o c}=m_{1} f_{c t}+m_{2} f_{c t}\left(h / l_{l o c}-1\right) \\
m_{1}=8 ; \quad m_{2}=2\end{array}$ \\
\hline 6 & Kvasha V.H. & $\left.f_{c, l o c}=f_{c}\left\{1+\frac{k}{f_{c t}} \|\left(\frac{A_{c 1}}{A_{c 0}}\right)^{\overline{2}}-1\right]\left\|f-f_{c t}-2\left(f^{2}-f f_{c t}+\frac{f_{c t}^{2}}{3}\right)^{2}\right\|\right\}$ \\
\hline 7 & Sokolov B.S. & $\begin{array}{c}f_{c, l o c}=f_{c} \frac{\operatorname{ctg} \alpha f_{c t}}{f_{c}}\left[2 m k\left(\frac{1}{\delta}-\cos \alpha \sin \alpha\right)+6\left(1+\sin ^{2} \alpha\right)+\sin ^{4} \alpha\right], \\
\operatorname{tg} \alpha=\frac{0.25 f_{c}}{f_{c t}}-1.56 ; \quad m=1 . .0 .6 ; \quad k=\frac{b}{l_{l o c}} ; \quad \delta=\frac{l_{l o c}}{h}\end{array}$ \\
\hline 8 & $\begin{array}{l}\text { Muguruma H., } \\
\text { Okamoto S. }\end{array}$ & $\begin{array}{c}f_{c, l o c}=f_{c}\left(\frac{A_{c 1}}{A_{c 0}}\right)^{k}\left(0.71+\frac{l}{(6.67 h-2.91 l)}\right), \\
k=\frac{7.61 h / l-3.54}{16.44 h / l-6.65}\end{array}$ \\
\hline 9 & Niyogi S.K. & $f_{c, l o c}=f\left\{0.42\left(\frac{l}{l_{l o c}}+2\right)-0.29\left[\left(\frac{l}{l_{l o c}}-1\right)^{2}+5.06\right]^{\frac{1}{2}}\right.$ \\
\hline 10 & Williams A. & $f_{c, l o c}=6.92 f_{c t}\left(\frac{A_{c 0}}{A_{c 1}}\right)^{-}$ \\
\hline 11 & Jensen B.C. & $f_{c, l o c}=f_{c}\left(0.2+0.8\left(\frac{A_{c 1}}{A_{c 0}}\right)^{\overline{2}}\right.$ \\
\hline
\end{tabular}




\section{Strength theoretical studies under crushing by the variational method}

In PoltNTU a variational method (VM) in the concrete plasticity theory [13-15] is developed. The method is confirmed by experimental studies under shear $[16,17]$ and is proposed for strength calculating under crushing.

The concrete element central one-sided crushing when the loading platform width is less than the element width is considered.

Presented in Fig. 4 the sample destruction kinematic scheme corresponds to the destruction experimental nature.

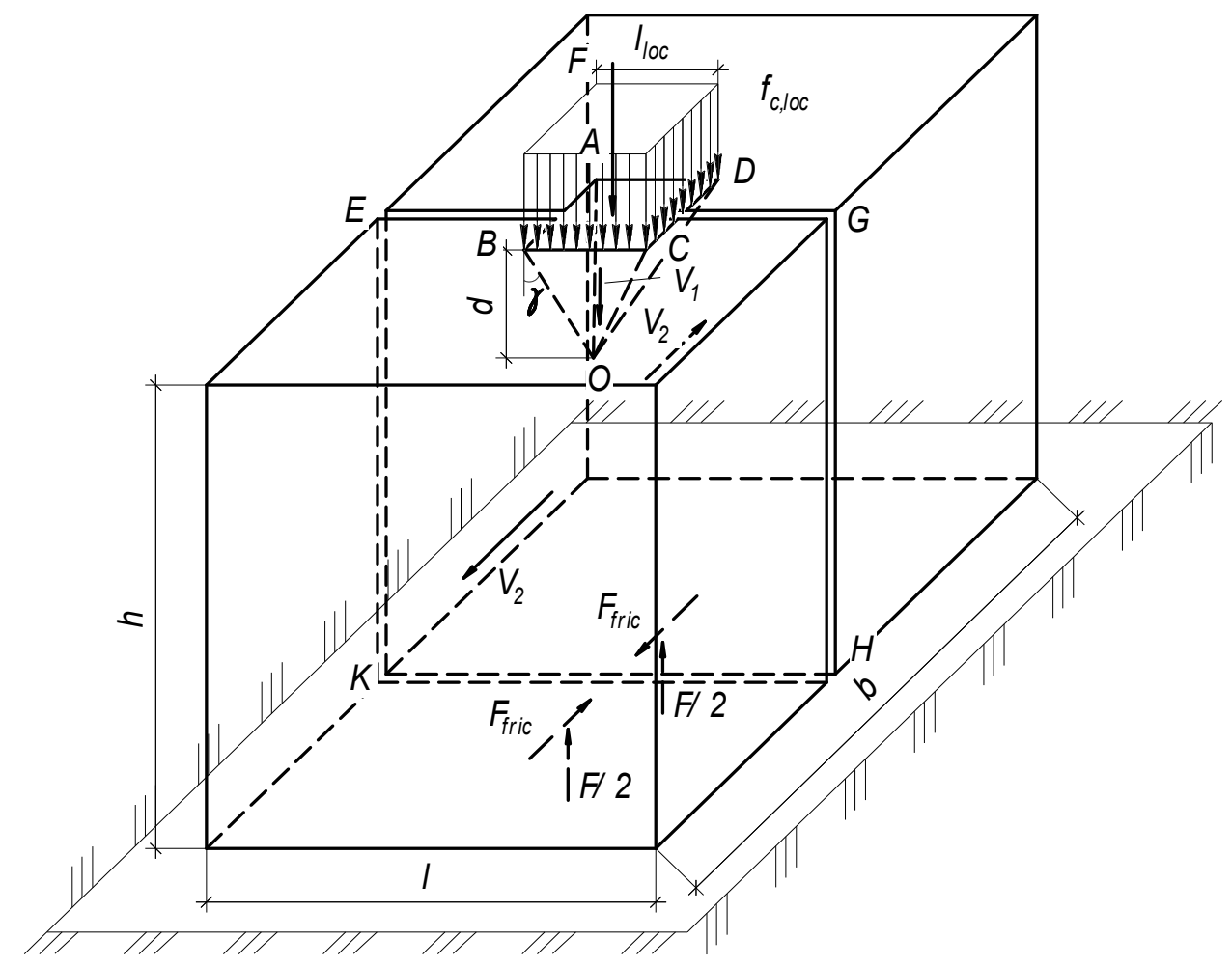

Fig. 4. The concrete element destruction kinematic scheme under central one-sided crushing.

In the limit state, a solid concrete element is divided into three rigid bodies: a pyramid with a base equal to the loading area, and two halves, separated by a splitting plane and a sliding surface. The pyramid moves down with the speed $V_{l}$, and the sample halves are removed horizontally at the same speeds $V_{2}$ and $-V_{2}$. The splitting plane passes through the sample gravity center in parallel to the short lateral face. On it, there are stresses that are taken equal to the concrete tensile strength $f_{c t d}$. The velocities ratio $k=V_{1} / V_{2}$ and the pyramid relative height $D=2 d / l_{l o c}$ are unknown for this task. On the destruction surface sections, the normal and the tangent speed component jumps are determined.

The ABO pyramid surface

$$
\left\{\begin{array}{l}
\Delta V_{n}=V_{2} \cos \gamma-V_{1} \sin \gamma \\
\Delta V_{t}=V_{2} \sin \gamma+V_{1} \cos \gamma
\end{array}\right.
$$


Its square

$$
A_{\mathrm{ABO}}=\frac{l_{l o c}^{2}}{4 \sin \gamma}
$$

The BCO pyramid surface

$$
\left\{\begin{array}{l}
\Delta V_{n}=V_{1} \sin \gamma \\
\Delta V_{t}=\sqrt{\left(V_{1} \cos \gamma\right)^{2}+V_{2}^{2}}
\end{array}\right.
$$

Its square

$$
A_{\mathrm{BCO}}=\frac{l_{l o c}^{2}}{4 \sin \gamma}
$$

Splitting surface EGHK

$$
\Delta V_{t}=V_{2}
$$

Its square

$$
A_{\mathrm{EGHK}}=\operatorname{lh}-\frac{l_{l o c}^{2}}{4 \operatorname{tg} \gamma}
$$

where $\operatorname{tg} \gamma=\frac{l_{l o c}}{2 d}$.

The virtual velocities principle functional for a three-dimensional stress state is recorded and equated to 0

$$
\begin{gathered}
I=2 m\left[B^{2}+0.25 \frac{\left(V_{2} \sin \gamma+V_{1} \cos \gamma\right)^{2}}{\left(V_{2} \cos \gamma-V_{1} \sin \gamma\right)^{2}}\right]\left(V_{2} \cos \gamma-V_{1} \sin \gamma\right) \frac{l_{l o c}^{2}}{4 \sin \gamma}+ \\
+2 m\left[B^{2}+0.25 \frac{\left(V_{1} \cos \gamma\right)^{2}+V_{2}^{2}}{\left(V_{1} \sin \gamma\right)^{2}}\right] V_{1} \sin \gamma \frac{l_{l o c}^{2}}{4 \sin \gamma}+2 f_{c t d} V_{2}\left(\operatorname{lh}-\frac{l_{l o c}^{2}}{4 \operatorname{tg} \gamma}\right)-f_{c, l o c} l_{l o c}^{2} V_{1}=0 .
\end{gathered}
$$

Limit load is defined as

$$
\frac{f_{c, l o c}}{m}=0.5\left[B^{2}+0.25\left(k^{2}\left(1+D^{2}\right)+D^{2}\right)\right]+\frac{0.5\left[B^{2}(D k-1)^{2}+0.25(k+D)^{2}\right]}{D k-1}+\frac{f_{c t d} k\left(\alpha^{12}-D\right)}{2 m},
$$

where $B^{2}=\left(1+\chi /(1-\chi)^{2}\right) / 3, \chi=f_{c t} / f_{c, p r i z m}, m=f_{c, p r i z m}-f_{c t}, \alpha^{\prime}=2 h / l_{l o c}$.

From the condition $f_{c, l o c}=\min$ unknown values $k$ and $\mathrm{D}$ are determined, after which the limit value is calculated.

Dependences for determining the bearing capacity under crushing from the strength determinants are constructed (Fig. 5).

The proposed kinematic scheme is also implemented at the cubes central one-sided local loading. The theoretical strength comparison with the experimental results indicates that the 
formula (8) with experiment is in good agreement ( $m=1.02, v=9.5 \%)$, however, it should be noted that the accepted kinematic scheme is implemented in relation to the element height to the loading platform $h / l_{c o c} \geq 4$.

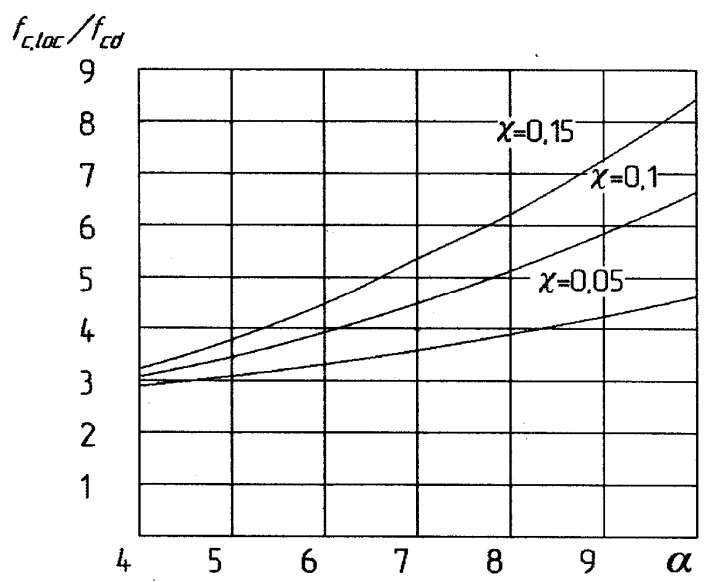

Fig. 5. The dependence for crushing strength determination for definite $\alpha=h / l_{l o c}$ and $\chi$.

In the larger loading areas case the stress uneven distribution on it may lead to the other destruction schemes implementation. In particular, the load is concentrated on the cargo area part (for example, on $1 / 4$ its area) and a possible split option along the planes parallel to the conditional (reduced) decomposition site diagonals. Scattering along diagonal sites may also be due to the experimental sample concrete structure heterogeneity.

If the load is transmitted through a platform which width is equal to the width of the element, the strength problem in the two-dimensional stress state case should be considered. Its solution is provided in [18]. The proposed calculation technique allows us to solve the strength problem for various central one-sided crushing cases, as well as to find its possible implementation limits.

\section{Conclusions}

During calculating of concrete elements strength under local compression, empirical dependencies are widely used, which have an application narrow scope, limited by the experimental conditions. The concrete plasticity theory is promising to improve the calculation methodology. The proposed formula for determining the concrete elements strength under central one-sided local compression in three-dimensional stress conditions is quite precise. Necessary accuracy is achieved by considering the destruction kinematics, which is observed in the experiments, and the strength determinants set.

\section{References}

1. D. H. Hladyshev, Resursoekonomni materialy, konstruktsiyi, budivli ta sporudy, Rovno, 29, 94-101, (2014)

2. S. Anjali, P. Lakshmi, IJIRT, 3(4), 173-179, (2016)

3. R. Breitenbücher, G. Meschke, F. Song, M. Hofmann, \& Y. Zhan, Proceedings of Joint ACI-fib International Workshop: Fibre Reinforced Concrete: from Design to Structural Applications (FRC 2014), Montreal, 417-429, (2014) 
4. V. Venckevičius, Journal of Civil Engineering and Management, 11(3), 243-248, (2005)

5. S. K. Niyogi, ASCE Journal of Structural Division, 114(3), 932-940, (1993)

6. Krishna Arathi, $\mathrm{S}$ Anjali, International Journal of Civil Engineering and Technology(UAE), 9(1), 41-47, (2018)

7. Fanbing Song, Steel Fiber Reinforced Concrete Under Concentrated Load, Ph.D thesis in Engineering science, Bochum, 169, (2017)

8. Zhenpeng Yu, Qiao Huang, Yushi Shan, \& Zheng Ren, Journal of Materials in Civil Engineering, 30(10), (2018)

9. V. V. Tur, N. A. Rak, Prochnost $i$ deformatsii betona $v$ raschetah konstruktsiy, Monografiya, Brest, 252, (2003)

10. B. M. Gladyishev Mehanicheskoe vzaimodeystvie elementov strukturyi i prochnost betona, Harkov, 168, (1987)

11. A. B. Piradov, Konstruktivnyie svoystva legkogo betona i zhelezobetona, Moskow, 135, (1973)

12. V. P. Mitrofanov, Stroitelnaya mehanika i raschet sooruzheniy, Moskow, 6, 23-28, (1990)

13. O. Dovzhenko, V. Pogrebnyi, I. Yurko, News NAS RK. Series of geology and technical science, 2 (428), 212-219, (2018)

14. V. Pohribnyi, O. Dovzhenko, O. Maliovana, International Journal of Engineering and Technology(UAE), 7 (3.2), 19-26, (2018)

15. O. Dovzhenko, V. Pohribnyi, I. Yurko, I. Shostak, Web of Conferences, 116, 02011, (2017)

16. O. Dovzhenko, V. Pohribnyi, L. Karabash, Journal of Engineering \& Technology (UAE), 7 (3.2), 354-359, (2018)

17. V. Pohribnyi, O. Dovzhenko, L. Karabash, I. Usenko, Web of Conferences, 116, 02026, (2017) 